\title{
Clinically Relevant Drug-Drug Interactions and Management Strategies: A Hospital-based Study
}

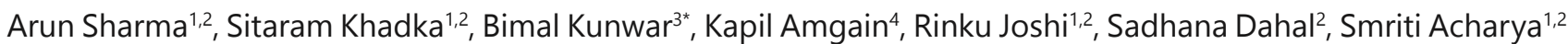
Mohit Thapa Magar ${ }^{1,2}$

\section{Author Info:}

${ }^{1}$ Shree Birendra Hospital, Chhauni, Kathmandu, Nepal

${ }^{2}$ Nepalese Army Institute of Health Sciences, Sanobharyang, Kathmandu, Nepal

${ }^{3}$ Nobel College, Pokhara University, Sinamangal, Kathmandu, Nepal

${ }^{4}$ Karnali Academy of Health Sciences, Jumla, Karnali, Nepal

Corresponding Author:

Bimal Kunwar;

Email/Contact:

kunwarbimal01@gmail.com; 00977-9841047646

\begin{abstract}
Background: Drug-drug interactions (DDIs) are one of the significant drugrelated problems encountered in clinical settings. A better understanding of the mechanisms, severity, and likely consequences of clinically significant DDIs are essential for proper medication therapy management (MTM). This study is conducted with the aim to aware clinical practitioners about clinically significant DDIs that occur in clinical settings and help them manage such events with appropriate knowledge and technique. Methods: A descriptive cross-sectional study was conducted at Shree Birendra Hospital, Kathmandu on the prescription of the medical out-patient department. A total of 483 prescriptions were selected randomly. A panel of physicians, pharmacologists, and clinical pharmacists under the supervision of a consultant physician was formed for verification of the reported DDIs using MICROMEDEX DRUG-REAX, Evaluation of Drug Interactions, Drug Interaction Facts, and Drug Interactions: Analysis and Management. The main outcome measure was obtained by the supervisor's endorsement of panelists' opinions about the clinical importance of DDIs.
\end{abstract}

Results: A total of 2006 medicines were prescribed in 483 prescription samples. The number of drugs per prescription was in a range from 2 to 11 with 4.15 on average. DDIs were found in $21.53 \%$ prescriptions $(n=104) .168$ DDIs were identified with major 32 (19\%), moderate 85 (51\%), and minor 51 (30\%) types. As per occurrence, the panel determined that 13 interactions were clinically significant.

Conclusion: The clinically significant DDIs identified by the panel are likely to occur in clinical settings. These can be preventable and can also be used for the beneficial effects in MTM based on the critical judgment of clinical staff and patient compliance. Adequate knowledge regarding the nature of DDIs, the inclusion of automated systems, and the inter-professional collaboration of a clinical team are liable to prevent and manage such events that help in rational drug therapy.

Keywords: Medication therapy management; Outpatients; Drug interactions; Prescriptions; Medication systems

\begin{tabular}{|c|c|}
\hline \multirow[t]{2}{*}{ QR Code } & Article Info \\
\hline & Received: 25 October 2020; Accepted: 29 December 2020; Published Online: 30 December 2020 \\
\hline s) 1 & How to cite this article in Vancouver Style? \\
\hline & $\begin{array}{l}\text { Sharma A, Khadka S, Kunwar B, Amgain K, Joshi R, Dahal S, Acharya S, Magar MT. Clinically Relevant } \\
\text { Drug-Drug Interactions and Management Strategies: A Hospital based Study. Europasian J Med Sci. } \\
\text { 2020;2(2):58-63. https://doi.org/10.46405/ejms.v2i1.246 }\end{array}$ \\
\hline & Disclaimer: \\
\hline & Conflict of Interest: None Declared; \\
\hline & $\begin{array}{l}\text { Copyright: ( } \odot 2020 \text { by author(s). This is an open access article distributed under the terms of the } \\
\text { Creative Commons Attribution International License } 4.0 @ \text { @ wich permits unrestricted use, } \\
\text { distribution, and reproduction in any medium, provided the original work is properly cited. }\end{array}$ \\
\hline & Publisher's Note: \\
\hline $\begin{array}{l}\text { The Europasian Journal } \\
\& \text { Ressearch Institute }(1 \\
\text { any published articles, }\end{array}$ & $\begin{array}{l}\text { Sciences (EJMS) (www.europasianjournals.org) is an official Journal of Nirvana Psychosocial Care Center } \\
\text { apscc.com). The Journal as well as publisher remain neutral with regards to any jurisdictional claims in } \\
\text { and the institutional affiliations of the authors. }\end{array}$ \\
\hline
\end{tabular}




\section{INTRODUCTION}

In the last few decades, medicine has become a leading reason for reduced mortality and disease burden. ${ }^{1}$ However, there is ample evidence that the co-administration of multiple drugs has caused many adverse effects, which may sometimes be very serious. ${ }^{2}$ The age-related physiological changes and associated pharmacologic profile of drugs, comorbidities, poly-pharmacy, and complex medication regimen to manage diseases make the serious drug-drug interactions (DDIs) more likely to occur. ${ }^{3}$ Clinically relevant DDIs are those interactions, which are harmful most likely in case if we fail to identify them.

Adverse drug reaction (ADR) is one of the major causes of hospital admission of which drug interactions are more common. ${ }^{4}$ Though the study of the potential of DDIs is an important part of drug development and market approval; comprehensive knowledge on DDIs and method of identifying potential interactions is a must for the health professionals in order to reduce the medical and economic losses. ${ }^{2}$ Drug interaction may lead to an altered response in terms of both safety and efficacy, where concomitant administration of the drugs may alter the absorption, distribution, metabolism, or excretion of the object drug. In vitro, in silico, and simulation are some of the methods that may help in prediction of DDIs. ${ }^{5}$ Most often drug interactions are predictable and preventable. ${ }^{6}$

Thus timely recognition of the potential drug interaction will prevent an undesired effect and help to achieve the goal of good clinical practice and offer an increase in drug safety. ${ }^{7}$ It helps in proper medication therapy management (MTM) with the rational use of drugs. ${ }^{8}$ In order to improve patient safety in the area of DDIs, identification of clinically important DDIs based upon a systematic review, and better strategies for prevention should be implemented through coordination among clinicians, pharmacologists, and pharmacists.

In this study, we aim to alert the clinical practitioners regarding clinically relevant DDIs and make strategies to manage such events.

\section{MATERIALS AND METHODS}

\section{Study design and setting}

A retrospective cross-sectional study was conducted in Shree Birendra Hospital on the prescription of medical out-patient department (MOPD) from March 2020 to August 2020. The ethical approval to conduct this study was obtained from the Institutional Review Committee of Nepalese Army Institute of Health Sciences, Kathmandu. Shree Birendra Hospital is a tertiary care level teaching hospital located in Chhauni, Kathmandu, Nepal. It is a central referral center for army personnel, veterans, and their dependents.

\section{Participants}

A panel composed of four specialists with proficiency in drug interactions consisting of consultant physician with expertise in nephrology and internal medicine (AS) as a supervisor, expert in pharmacology and clinical pharmacy $(\mathrm{SK})$, hematology and internal medicine (RJ), and orthopedics (MTM) was formed. The panel was supported by the other three experts, a clinical pharmacist (SD), an internal medicine resident (SA), and pharmacology and clinical pharmacy expert (BK) for examinations, preparation, and verification of reports of DDIs.

\section{Interventions}

A total of 483 prescriptions were selected randomly. Drug interaction checker system such as MICROMEDEX DRUG-REAX, Evaluation of Drug Interactions, Drug Interaction Facts, Drug Interactions: Analysis and Management was conducted. The main outcome measure was obtained by the supervisor's endorsement of panelists' opinions about the clinical importance of DDIs.

A three-stage process was carried out for the identification of clinically relevant DDIs. The reports were then evaluated by a panel of experts using a DDI checker website. Object and precipitant drugs were identified for each interaction. Object drugs are those whose therapeutic effects get altered with the action of precipitant drugs.

\section{Selection of Candidate DDIs}

As a stage I, candidate DDIs from existing drug interaction compendia were selected. Interactions were graded as major, moderate, or minor referring to the four commonly used DDI compendia [Evaluation of Drug Interactions ${ }^{9}$, Drug Interaction Facts ${ }^{10}$, Drug Interactions: Analysis and Management ${ }^{11}$, and MICROMEDEX (DRUG-REAX ${ }^{12}$ ) system] and then cross-referenced to each other. Specific criteria for the rating were developed as all compendia may differ in a rating system for DDIs. In case of being listed in three of the four compendia, DDIs were selected for further review. The interactions associated with products not 
perceived from prescription such as alternative medicines, foods, or alcohol were not taken into consideration. Prescriptions from patients visiting sub-units in the MOPD such as nephrology and diabetic OPDs or visiting OPDs but including MOPD were evaluated. Prescriptions from OPDs other than medical OPD, wards, emergency, and intensive care unit (ICU) were not included. The prescriptions having more than one drug were evaluated. DDls where the drugs commonly used in combination for beneficial therapeutic effect and those identified upon discontinuation of one of the agents were also excluded.

\section{Gathering evidence about DDIs}

The evidences about identified DDIs were gathered in stage II. The references cited for each DDIs in compendia were reviewed. The assembled literature for each DDI was examined by two authors (SD and SA). The evidence report was prepared for all DDIs. Another author (BK) verified the adequateness of each evidence report. After verification, the reports were sent to an expert panel for review.

\section{Evaluation of candidate DDIs}

At stage III, the clinically relevant and well-supported DDIs were focused on for future reference and intervention. A document containing a summary and bibliography of each interaction along with the copies of the key articles were submitted to the expert panel. The interaction types were classified into major, moderate, and minor. The classifications below are used as a guideline.

\section{RESULTS}

A systematic evaluation of the literature and an expert-panel process were used for the identification of clinically important DDls. The number of drugs prescribed in the sample was 4.15 on average ranging from 2 to 11 drugs. A total of 2006

Clinically significant interactions Major where the risks outweigh beneficial effects.

Suggestion - avoid combinations

$\begin{array}{ll}\text { Reasonably clinically significant } \\ \text { interactions averate } & \begin{array}{l}\text { Suggestion- avoid or use only } \\ \text { under special conditions. }\end{array}\end{array}$

Nominally clinically significant where the drugs can be

Minor Suggestion- use after assessing risk with monitoring, take counteracting steps with proper counseling

medicines were prescribed in 483 prescriptions. DDls were found in $21.53 \%$ prescriptions $(n=104)$. The panel evaluated 168 DDIs amongst all the assessed prescriptions. The types of interactions among those were found to be major 32 (19\%), moderate 85 (51\%), and minor 51(30\%) (Figure 1).

Table 1 enlists the number of interactions identified in each compendium. The candidate DDIs were then cross-referenced to each other to evaluate total DDIs of different types. After all considerations, the expert panel decided to exclude therapeutically beneficial combinations and concluded 13 DDIs as

Table 1: Interactions listed by drug interaction compendia

$\begin{array}{lll}\text { SN } & \text { Compendia } & \text { Interactions (n) } \\ 1 & \text { MICROMEDEX DRUG-REAX } & 105 \\ 2 & \begin{array}{l}\text { Evaluation of Drug } \\ \text { Interactions }\end{array} & 115 \\ 3 & \begin{array}{l}\text { Drug Interaction Facts } \\ \text { Drug Interactions: Analysis } \\ \text { and Management }\end{array} & 55 \\ \end{array}$

Table 2: DDIs selected by the panel as having the greatest clinical importance

\begin{tabular}{|c|c|c|c|}
\hline $\begin{array}{l}\mathrm{S} \\
\mathrm{N}\end{array}$ & Object drug & $\begin{array}{l}\text { Precipitant } \\
\text { drug }\end{array}$ & Likely Hazards \\
\hline 1 & Atorvastatin & Azithromycin & Muscles toxicity \\
\hline 2 & Clopidogrel & Omeprazole & $\begin{array}{l}\text { Reduced } \\
\text { efficacy } \\
\text { in heart attack } \\
\text { or stroke } \\
\text { prevention }\end{array}$ \\
\hline 3 & Levofloxacin & Prednisolone & Tendinitis \\
\hline 4 & Warfarin & Metronidazole & $\begin{array}{l}\text { Bleeding } \\
\text { complications }\end{array}$ \\
\hline 5 & Enalapril & Allopurinol & $\begin{array}{l}\text { Anaphylaxis } \\
\text { and myocardial } \\
\text { infarction }\end{array}$ \\
\hline 6 & \multirow{2}{*}{$\begin{array}{l}\text { Metformin } \\
\text { Furosemide }\end{array}$} & Enalapril & Hypoglycemia \\
\hline 7 & & Tizanidine & Hypotension \\
\hline 8 & Metoprolol & Theophylline & $\begin{array}{l}\text { Breathing } \\
\text { problems }\end{array}$ \\
\hline 9 & \multirow{2}{*}{$\begin{array}{l}\text { Methotrexate } \\
\text { Methotrexate }\end{array}$} & Omeprazole & $\begin{array}{l}\text { Methotrexate } \\
\text { toxicity }\end{array}$ \\
\hline 10 & & Pantoprazole & $\begin{array}{l}\text { Methotrexate } \\
\text { toxicity }\end{array}$ \\
\hline 11 & \multirow{2}{*}{$\begin{array}{l}\text { Insulin } \\
\text { Warfarin }\end{array}$} & Ciprofloxacin & Hypoglycemia \\
\hline 12 & & Diclofenac & $\begin{array}{l}\text { Bleeding } \\
\text { complications }\end{array}$ \\
\hline 13 & Losartan & $\begin{array}{l}\text { Spirono- } \\
\text { lactone }\end{array}$ & Hyperkalemia \\
\hline
\end{tabular}


Interactions Identified

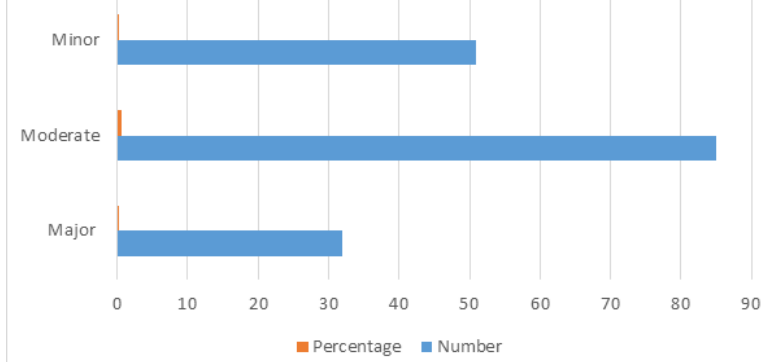

Figure 1: Number and percentage of types of interactions identified

clinically relevant (Table 2). Most of the interacting agents of clinically relevant DDIs were found to be drugs acting on the cardiovascular system (Atorvastatin, Clopidogrel, Warfarin, Enalapril, Furosemide, Metoprolol, Losartan, and Spironolactone) followed by antibiotics (Azithromycin, Ciprofloxacin, and Levofloxacin), proton pump inhibitors (Omeprazole and Pantoprazole), drugs acting on the musculoskeletal system (Diclofenac, Allopurinol, and Tizanidine), anti-diabetic agents (Metformin and Insulin), antimetabolites (Methotrexate), steroid (Prednisolone), and bronchodilator (Theophylline).

\section{DISCUSSION}

Based on this study, among several subsets of interacting drug combinations, the expert panel concluded 13 interactions to be more common and clinically relevant. A similar study conducted in the United States concluded 25 interactions as a clinically important and possible to occur in community and ambulatory pharmacy settings. ${ }^{13}$ The types of interactions observed in our study were major 32 (19\%), moderate 85 (51\%), and minor $51(30 \%)$. DDls were found in $21.53 \%$ of the total prescription samples, which somehow coincides with a study conducted in Bharatpur District Hospital, Nepal where it was $19.1 \%{ }^{14}$ However, the result varies considerably with the findings of a study conducted in a tertiary care teaching hospital of Gujarat, India where it was $71.50 \% .^{15}$

Drug interaction compendia include a large number of drug interactions. However, these references may differ significantly. As DDI compendia seem to be dependent on a few authors or a small number of editors to evaluate drug interactions, consistent results related to DDIs demands great effort. ${ }^{16}$ Likewise, drug manufacturers have become increasingly careful in the identification and reporting of DDIs. ${ }^{13}$ Automated system of computerized drug interaction screening is useful for rational use of drugs. ${ }^{17}$ It is used widely for identifying and reducing the possible harmful interactions, however, results of computer systems also differ greatly, to which drug interactions trigger warnings. ${ }^{6}$ Despite the numerous advantages of information technology, drawbacks such as insufficient patient data and inappropriate medical reasoning may sometimes make the identification of drug interaction difficult. Practitioners' alignment with the traditional way and feeling less comfortable with the automated systems may be another barrier in information technology innovations for rational drug use. ${ }^{18}$ Many prescribing decisions are made by physicians based upon individual patient characteristics, disease state, and various economic and social factors ${ }^{19,20}$ which may be hard to manage solely by relying on computer software. ${ }^{21}$

The automated prescribing systems with sufficient data to support medical reasoning could be a better solution to reduce the medication errors. ${ }^{22}$ Such system links to different information such as patients' medication history, interactions and ADR alerts, formulary drugs, standard treatment guidelines inform prescribers instantly to a correct therapeutic regimen with proper accessory information. ${ }^{23}$ The objective of our study was to identify DDIs to make healthcare practitioners such as physicians, pharmacologists, pharmacists, and nurses vigilant about such events.

Though DDIs have become a serious problem due to the availability of potent drugs and polypharmacy practice, many drug interactions can be predicted and prevented. ${ }^{24}$ DDIs cause failure of therapy leading to severe harm to the patients. But, the interactions can be used in therapeutics with proper monitoring for benificial effects as well. The critical judgment of clinical staff and patient compliance are essential in this regard. However, it is better to have no DDIs in therapy.

Therefore, to prevent DDIs, close monitoring is required in susceptible patients and in patients taking multiple drug therapy. DDIs can be recognized by maintaining patient medication history and checking the interactions based on the existing literature and automated software. Healthcare practitioners should be on the lookout for the timely recognition and prevention of DDIs. ${ }^{25}$ Thus, the drug interaction monitoring programs are required to set up in healthcare setting. Such programs detect the drug interactions occurring in the healthcare setting, develop intervention 
approaches, and assess the impact of the interaction.

The intervention strategies may include discussion among the peers, the drug and therapeutics committee members, and also with overall healthcare professionals. Giving alternative drugs that may cause major interactions or adding drugs that counteract the toxic effects of another drug or changing the dose or making adequate time gap between administrations of drugs with interacting potential also may be of help. ${ }^{26}$ Being aware of the drugs being used and avoiding unnecessary drug therapy is a must to prevent interactions. ${ }^{24}$

Limitations: Based on the best evidence available, subjective judgments are made by the expert panels. The results may be dependent on the judgments of members of an expert panel. These interactions represent a selected set of all probable DDIs. Though the identified DDIs in this study were for the hospital setting only, other clinically important DDIs should also be identified and prevented depending on the setting and nature of drugs.

The patient-specific relevance of a particular drug interaction is tough to determine referring to the tool used in this study alone given the large number of variables that may apply.

We did not exclude prescriptions from other departments in case of patients' multiple OPD visits along with MOPD. In such a case, drugs prescribed from one department can interact with drugs prescribed from another department for the same patient.

All the drug-reference books or information resources containing information related to DDIs were not consulted. The compendia most commonly used by healthcare professionals to determine DDIs were referred. Lastly, the systematic evaluation of health outcomes and expenditures associated with the 13 DDIs considered clinically relevant are not performed.

\section{CONCLUSION}

The drug interactions are identified by a panel of experts using a standard evaluation tool. These represent a category of interactions acclaimed by drug interaction compendia and are considered to be clinically important and likely to occur in clinical settings. Clinically significant DDIs can be preventable and can also be used for the beneficial effects in MTM in clinical settings based on the critical judgment of clinical staff and patient compliance. Based on the findings, we suggest different departments to check drugs prescribed by other departments in case of patients' multiple OPD visits. We encourage healthcare practitioners to prevent patients from taking these interacting medications and use an automated system to focus interaction alerts on such and other important DDIs. Ample knowledge regarding DDIs, the inclusion of automated system in prescribing and dispensing, and inter-professional collaboration of a clinical team are liable to prevent and manage such events and help in rational drug therapy.

\section{REFERENCES}

1. World Health Organizations. The Pursuit of Responsible Use of Medicines: Sharing and Learning from Country Experiences. World Health Organizations; 2012. [Google Scholar]

2. Takarabe M, Shigemizu D, Kotera M, Goto S, Kanehisa M. Network-based analysis and characterization of adverse drug-drug interactions. J Chem Inf Model. 2011 Nov;51(11):2977-85. https://doi.org/10.1021/ci200367w [Google Scholar] [PubMed]

3. Alhouzani T, Saleem M, Khadka S, Al-Subari S, Shrestha D, Butt I. Toxicity Profiles of Commonly Used Anti-Inflammatory Drugs in Geriatrics. Eur J Med Sci. 2020;2(2). https://doi.org/10.46405/ejms. v2i2.107 [Google Scholar]

4. Köhler GI, Bode-Böger SM, Busse R, Hoopmann $M$, Welte $T$, Böger RH. Drug-drug interactions in medical patients: effects of in-hospital treatment and relation to multiple drug use. Int J Clin Pharmacol Ther. 2000 Nov;38(11):504-13. https:// doi.org/10.5414/CPP38504 [Google Scholar] [PubMed]

5. Zhang L, Zhang YD, Zhao P, Huang S-M. Predicting drug-drug interactions: an FDA perspective. AAPS J. 2009 Jun;11(2):300-6. https://doi.org/10.1208/ s12248-009-9106-3 [Google Scholar] [PubMed]

6. Juurlink D, Mamdani M, Kopp A, Laupacis A, Redelmeier D. Drug-drug interactions among elderly patients hospitalized for drug toxicity. Jama. 2003;289(13):1652-8. https://doi.org/10.1001/ jama.289.13.1652 [Google Scholar] [PubMed]

7. van Roon EN, Flikweert $\mathrm{S}$, le Comte $\mathrm{M}$, Langendijk PNJ, Kwee-Zuiderwijk WJM, Smits P, et al. Clinical relevance of drug-drug interactions : a structured assessment procedure. Drug Saf. 2005;28(12):11319. https://doi.org/10.2165/00002018-20052812000007 [Google Scholar] [PubMed]

8. Aparasu R, Baer R, Aparasu A. Clinically important potential drug-drug interactions in outpatient settings. Res Social Adm Pharm. 2007 Dec;3(4):426- 
37. https://doi.org/10.1016/j.sapharm.2006.12.002 [Google Scholar] [PubMed]

9. Evaluations of drug interactions. First DataBank, St. Louis, Mo. The Hearst Corporation; 2001.

10. Drug interaction facts. St. Louis, Mo.: Facts and Comparisons; 2001.

11. Drug interactions: analysis and management. St. Louis, Mo.: Facts and Comparisons; 2001.

12. DRUG-REAX system. Micromedex, Greenwood Village, Colo; 2001

13. Malone $D$, Armstrong E, Abarca J, Grizzle A, Hansten $P$, Van Bergen $R$, et al. Identification of serious drug-drug interactions: results of the partnership to prevent drug-drug interactions. J Am Pharm Assoc. 2004;44(2):142-51. https:// doi.org/10.1331/154434504773062591 [Google Scholar] [PubMed]

14. Shrestha R, Prajapati S. Assessment of prescription pattern and prescription error in outpatient Department at Tertiary Care District Hospital, Central Nepal. J Pharm policy Pract. 2019;12:16. https://doi.org/10.1186/s40545-019-0177-y [Google Scholar] [PubMed]

15. Kothari N, Ganguly B. Potential Drug - Drug Interactions among Medications Prescribed to Hypertensive Patients. J Clin Diagn Res. 2014 Nov;8(11):HC01-4. https://doi.org/10.7860/ JCDR/2014/10032.5091 [Google Scholar] [PubMed]

16. Malone D, Abarca J, Hansten P, Grizzle A, Armstrong $E$, Van Bergen $R$, et al. Identification of serious drug-drug interactions: Results of the partnership to prevent drug-drug interactions. Am J Geriatr Pharmacother. 2005;3(2):65-76. https://doi. org/10.1016/j.amjopharm.2005.05.001 [Google Scholar] [PubMed]

17. Egger SS, Drewe J, Schlienger RG. Potential drugdrug interactions in the medication of medical patients at hospital discharge. Eur J Clin Pharmacol. 2003 Mar;58(11):773-8. https://doi.org/10.1007/ s00228-002-0557-z [Google Scholar] [PubMed]

18. Mechanic D. Rethinking Medical Professionalism: The Role of Information Technology and Practice Innovations. Milbank Q [Internet]. 2008;86(2):327-58. https://doi.org/10.1111/j.14680009.2008.00523.x [Google Scholar] [PubMed]
19. Manasse Jr H. Medication use in an imperfect world: drug misadventuring as an issue of public policy, part 2. Am J Heal Pharm. 1989;46(6):114152. https://doi.org/10.1093/ajhp/46.6.1141 [Google Scholar] [PubMed]

20. Manasse $\mathrm{Jr} \mathrm{H}$. Medication use in an imperfect world: drug misadventuring as an issue of public policy, part 1. Am J Heal Pharm. 1989;46(5):929-44. https://doi.org/10.1093/ajhp/46.5.929 [Google Scholar] [PubMed]

21. Soumerai SB, Lipton HL. Computer-based drugutilization review--risk, benefit, or boondoggle? N Engl J Med. 1995 Jun;332(24):1641-5. https:// doi.org/10.1056/NEJM199506153322411 [Google Scholar] [PubMed]

22. Crane J, Crane FG. Preventing Medication Errors in Hospitals through a Systems Approach and Technological Innovation: A Prescription for 2010. Hosp Top [Internet]. 2006;84(4):3-8. https://doi. org/10.3200/HTPS.84.4.3-8 [Google Scholar] [PubMed]

23. Armstrong EP, Chrischilles EA. Electronic Prescribing and Monitoring Are Needed to Improve Drug Use. Arch Intern Med. 2000;160(18):2713-4. https://doi. org/10.1001/archinte.160.18.2713 [Google Scholar] [PubMed]

24. Prescott LF. Clinically important drug interactions. Drugs. 1973;5(3):161-86. https://doi. org/10.2165/00003495-197305030-00001 [Google Scholar] [PubMed]

25. Raval D, Saraswathy N, Meghani N, Shah H. Contribution of drug interactions to burden of preventable ADR'S: Approches to predict and prevent drug interactions. Indian J Pharm Pract. 2011;4(1). [Google Scholar]

26. Murphy JE, Malone DC, Olson BM, Grizzle AJ, Armstrong EP, Skrepnek GH. Development of computerized alerts with management strategies for 25 serious drug-drug interactions. Am J Heal Pharm. 2009;66(1):38-44. https://doi.org/10.2146/ ajhp070046 [Google Scholar] [PubMed] 